\title{
Convergence properties of Ibragimov-Gadjiev-Durrmeyer operators
}

\author{
EMre DeNiZ and ALi ARAL
}

\section{ABSTRACT.}

The purpose of the present paper is to study the local and global direct approximation properties of the Durrmeyer type generalization of Ibragimov Gadjiev operators defined in [Aral, A. and Acar, T., On Approximation Properties of Generalized Durrmeyer Operators, (submitted)]. The results obtained in this study consist of Korovkin type theorem which enables us to approximate a function uniformly by new Durrmeyer operators, and estimate for approximation error of the operators in terms of weighted modulus of continuity. These results are obtained for the functions which belong to weighted space with polynomial weighted norm by new operators which act on functions defined on the non compact interval $[0 . \infty)$. We finally present a direct approximation result.

\section{REFERENCES}

[1] Aral, A., Approximation by Ibragimov-Gadjiev operators in polynomial weighted space, Proc. Inst. Math. Mech. Natl. Acad. Sci. Azerb., 19 (2003), 35-44

[2] Aral, A. and Acar, T., On Approximation Properties of Generalized Durrmeyer Operators, (submitted)

[3] Aral, A. and Gupta, V., On the Durrmeyer type modification of the q-Baskakov type operators, (English summary) Nonlinear Anal., 72 (2010), No. 3-4, 1171-1180

[4] Agratini, O., On the iterates of a class of summation type linear positive operators, Comput. Math. Appl., 55 (2008) 3795-3801

[5] Coskun, T., On a construction of positive linear operators for approximation of continuous functions in the weighted Spaces, Journal of Comput. Anal. and Appl., Vol. 13, No. 4, 756-770

[6] Doğru, O., On a certain family of linear positive operators, Turkish J. Math., 21 (1997)

[7] Gadjiev, A. D., Efendiyev, R. O. and Ibikli, E., On Korovkin type theorem in the space of locally integrable functions, Czech. Math. J., 53 (128) (2003), No.1, 45-53

[8] Gadjiev, A. D. and Aral, A., Weighted Lp -approximation with positive linear operators on unbounded sets, Appl. Math. Lett., 20 (2007), No. 10, 1046-1051

[9] Gadzhiev, A. D., Theorems of the of P. P Korovkin type theorems, Math. Zametki, 20 (1976), No. 5, 781-786, Math. Notes, 20 (1976), No. (5-6) 996-998 (English Translation)

[10] Ghorbanalizadeh, Arash M., On the order of weighted approximation of unbounded functions by some generalizations of Gadjiev-Ibragimov operators, J. Appl. Anal., 20 (2014), No. 1, 87-92

[11] Heilmann, M., Direct and converse results for operators of Baskakov-Durrmeyer type, Approx. Theory and Its Appl., 5 (1988), No. 1, 105-127

[12] Ibragimov, I. I. and Gadjiev, A. D., On a certain Family of linear positive operators, Soviet Math. Dokl., English Trans., 11 (1970), $1092-1095$

[13] Mazhar, S. M. and Totik, V., Approximation by modified Szasz operators, Acta Sci. Math., 49 (1985), 257-269

[14] Sahai, A. and Prasad, G., On simultaneous approximation by modified Lupas operators, J. Approx. Theory, 45 (1985), No. 12, 122-128

[15] Ispir, N., On modified Baskakov operators on weighted spaces, Turk. J. Math., 26 (2001), No. 3, 355-365

[16] Ulusoy, G. and Aral, A., Approximation Properties of Ibragimov-Gadjiev Durrmeyer operators in $L_{p}[0, \infty)$, (submitted)

DEPARTMENT OF MATHEMATICS

FACULTY OF SCIENCE AND ARTS

KIRIKKALE UNIVERSITY

71450 YAHSIHAN, KIRIKKALE, TURKEY

E-mail address: emredeniz--@hotmail.com

DEPARTMENT OF MATHEMATICS

FACULTY OF SCIENCE AND ARTS

KIRIKKALE UNIVERSITY

71450 YAHSIHAN, KIRIKKALE, TURKEY

E-mail address: aliaral73@yahoo.com

Key words and phrases. Durrmeyer operators, Ibragimov-Gadjiev operators, Korovkin theorem, rate of convergence, modulus of continuity, weighted approximation. 